\title{
REVISED Case Report: A case report of dry tap during
}

\section{ventriculostomy [version 2; peer review: 2 approved, 1}

\section{approved with reservations]}

\author{
Sunil Munakomi (i), Binod Bhattarai \\ Department of Neurosurgery, College of Medical Sciences, Bharatpur, 44207, Nepal
}

V2 First published: 07 Jul 2015, 4:188

https://doi.org/10.12688/f1000research.6750.1

Latest published: 02 Oct 2015, 4:188

https://doi.org/10.12688/f1000research.6750.2

\section{Abstract}

Pneumocephalus following ventriculoperitoneal (VP) shunt insertion is an exceptionally rare occurrence. We report such an event after attempting ventricular puncture (ventriculostomy) for VP shunt insertion and then discuss the management of the same. Dry tap can lead to multiple attempts for ventriculostomy with the associated added risks of complications, as well as complicating the subsequent management. In addition, there is an increased risk of tension pneumocephalus, seizure and shunt failure due to a blockage by air bubbles. Our patient presented with features of raised intracranial pressure two months following craniotomy and evacuation of traumatic subdural hematoma. External ventricular puncture revealed egress of CSF under pressure. Upon attempting VP shunting for posttraumatic hydrocephalus, we experienced dry tap during ventricular puncture that complicated further management. We placed the proximal shunt in the presumed location of the foramen of Monro of ipsilateral frontal horn of lateral ventricle and did not remove the external ventricular drain. Post-operative CT scan revealed pneumoventriculi as the cause for the dry tap during ventricular puncture. Patient was managed with $100 \%$ oxygen. He showed gradual improvement and was later discharged. This case shows that variations in the procedure, including head down positioning, adequate cruciate dural incision prior to cortex puncture, and avoiding excessive egress of CSF can help to prevent such complications.

\section{Keywords}

Dry tap, Pneumocephalus, Management

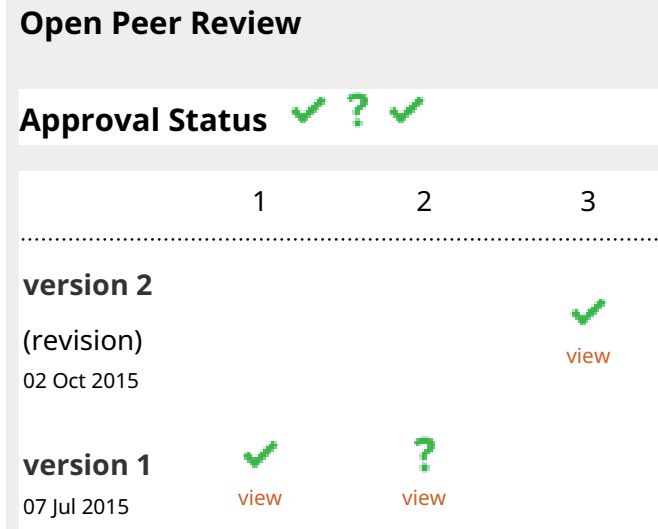

1. Guo-Yi Gao, Shanghai Jiao Tong University, Shanghai, China

2. Roman Bosnjak, University Medical Centre Ljubljana, Ljubljana, Slovenia

3. Guru Dutta Satyarthee, All India Institute of Medical Sciences, New Delhi, India

Luis Rafael Moscote-Salazar (D), RED

LATINO. Latin American Trauma \& Intensive Neuro-Care Organization, Bogota, Colombia Any reports and responses or comments on the article can be found at the end of the article. 
Corresponding author: Sunil Munakomi (sunilmunakomi@gmail.com)

Competing interests: The authors declared no competing interests.

Grant information: The author(s) declared that no grants were involved in supporting this work.

Copyright: @ 2015 Munakomi S and Bhattarai B. This is an open access article distributed under the terms of the Creative Commons Attribution License, which permits unrestricted use, distribution, and reproduction in any medium, provided the original work is properly cited.

How to cite this article: Munakomi S and Bhattarai B. Case Report: A case report of dry tap during ventriculostomy [version 2; peer review: 2 approved, 1 approved with reservations] F1000Research 2015, 4:188 https://doi.org/10.12688/f1000research.6750.2

First published: 07 Jul 2015, 4:188 https://doi.org/10.12688/f1000research.6750.1 


\section{REVISED Amendments from Version 1}

We have addressed the reasons to opt for the EVD insertion prior to the VP shunting in the patient. We also have discussed the probable reason for the pheumocephalus in our case.

See referee reports

\section{Introduction}

Pneumocephalus is defined as the presence of air within the calvarium. It often follows trauma but is also a common sequelae of intracranial surgery ${ }^{1,2}$. Tension pneumocephalus is a life-threatening emergency that necessitates immediate surgical intervention ${ }^{3}$. It is rarely reported after cerebrospinal fluid (CSF) diversion procedures $^{4,5}$. We present a rare case of tension pneumocephalus, resulting in dry tap during ventriculostomy and discuss its subsequent management.

\section{Case report}

Herein we report a case of a 35-year-old male from Nawalparasi, Nepal, who had undergone a craniotomy and evacuation of acute subdural hematoma following an automobile accident 2 months before admission to our institution. He presented with complaints of an abnormal gait, with a tendency to fall backwards and also with features of frontal lobe-related incontinence. There were no significant past medical illnesses. He was taking Sodium Valproate (300 $\mathrm{mg}$ oral three times daily) as seizure prophylaxis following the traumatic head injury and surgical intervention for the same 2 months previously. Fundus examination revealed the presence of papilledema. A head computerized tomography (CT) scan revealed the presence of evolving hydrocephalus. To rule out hydrocephalus ex vacuo due to volume loss and changes in CSF dynamics subsequent to the previous accident, external ventricular drainage (EVD) was placed which revealed egress of CSF under pressure. The reasons for opting to choose EVD prior to VP shunting are threefold. Firstly, we had to rule out post traumatic hydrocephalus ex vacuo by measuring the opening pressure of the CSF egress and looking for the neurological improvement in the patient following CSF diversion. Secondly, since we not have the programmable VP shunting available, we need to appropriately choose the Chabra shunt depending on the opening pressure so as to prevent either over drainage or under drainage of CSF. Lastly, since it was a post traumatic case, we need to measure the CSF protein (as it may be increased from the lysed traumatic subarachnoid blood) and also we need to rule out subclinical meningitis. Both these may be the reasons for shunt failure. Following EVD, the patient showed gross improvement in his previous deficits. CSF sugar and protein was within range. Gram stain was negative for any bacteria. Repeat CT scan post EVD did not reveal any pneumocephalus. Thereafter he was scheduled for insertion of a VP shunt. EVD was clamped for 6 hours prior to the procedure to facilitate the ventricular tap. During insertion of the VP shunt, there was dry tap during an attempt of ventriculostomy from the Kocher's point. We made two further attempts to ensure the correct trajectory of the shunt end and also to reflush the shunt end to prevent blockage due to blood clots and cell debris. We placed the shunt tip in the presumed location of the foramen of Monro of the frontal horn of ipsilateral lateral ventricle. We did not remove the EVD, hoping that it would act as a safety channel for CSF bypass had we missed the correct trajectory for the VP shunt.

A postoperative scan revealed the presence of tension pneumocephalus and pneumoventriculi (Figure 1 and Figure 2). The patient was managed with $100 \%$ oxygen for 3 days and was continued on antiepileptic medications at the same dose intravenously. Stringent neurological monitoring was undertaken to evaluate early neurological deterioration due to tension pneumocephalus. Pupils were routinely assessed to look for hippus (a clinical marker of epilepsy). Patient was extubated the following morning. A repeat CT scan on the $6^{\text {th }}$ day post-operation showed that the proximal shunt was in the third ventricle (Figure 3) and there was complete resolution of the condition. The EVD was subsequently removed with no neurological deterioration of the patient on $7^{\text {th }}$ day after operation. The patient then started to walk with support from the $8^{\text {th }}$ day post-operation, and he slowly improved in gait. Patient went home walking with minimal support on the $14^{\text {th }}$ day post-operation. Patient had also regained his bladder control within that time. Patient returned,

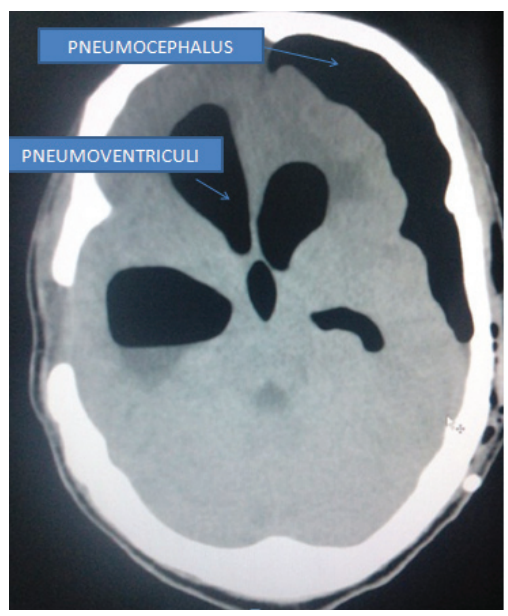

Figure 1. CT image showing presence of pneumocephalus and pneumoventriculi.

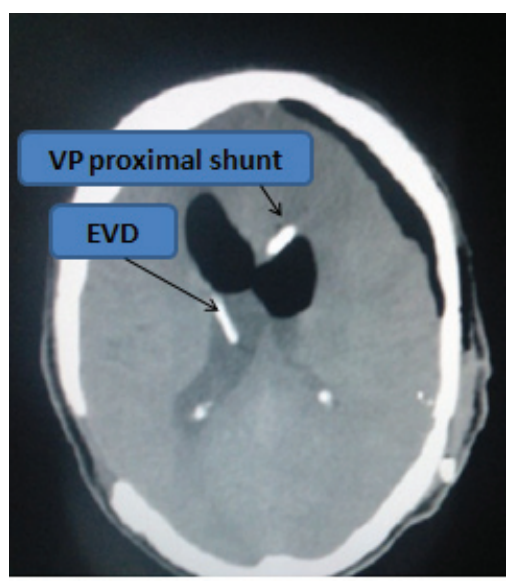

Figure 2. CT image showing location of EVD and VP Shunt proximal end. 


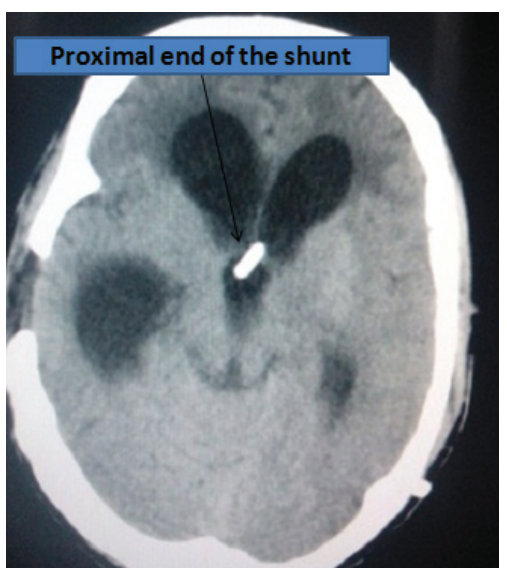

Figure 3. CT image confirming location of proximal end of VP shunt.

walking on his own 1 month later for his follow up in the outpatient department His gait was normal with no features of retropulsion. The shunt chamber was functioning well and his bowel habits were normal. Compliance in continuation of Sodium valproate therapy (at the aforementioned dose) was also ensured.

\section{Discussion}

Pneumocephalus usually occurs after head trauma, skull base fractures, and associated CSF fistulas ${ }^{1}$. The incidence of this entity was reported to be as high as $100 \%$ following supratentorial craniotomies ${ }^{6}$. On the other hand, tension pneumocephalus is a neurosurgical emergency that requires rapid surgical intervention. Pneumocephalus as a complication of CSF diversion procedures is rare ${ }^{5}$. Diagnosis is mainly based on clinical examination and computerized tomography (CT) scan ${ }^{4}$. Two CT findings that characterise the condition - the 'Mount Fuji' sign and the 'air bubble' sign - have been described by Ishiwata $e t a l .^{7}$.

There are two factors that are thought to be responsible for tension pneumocephalus development. The first is a decrease in intracranial pressure due to a sudden egress of CSF; the second is the presence of a craniodural defect that works as a one way valve allowing air inflow to the intracranial space and preventing outflow ${ }^{4}$. It is claimed that moderate cerebral atrophy might play a role ${ }^{1}$.

The duration of the shunt surgery must be as short as possible and CSF leakage during the connection of the shunt system must be avoided. Another factor that can lead to undesirable outcomes can be introduced during the puncturing of the cortex. Adequate cruciate incision must be given to prevent the passage of environmental air into the subdural space. Filling the subdural space on the ventriculostomy site with irrigation fluid until overflowing might help the outflow of air from the intracranial vault, reducing the risk of this rare complication. Cortical atrophy may have also had an effect on isolated air collection within the subdural space. In our case, another remote possibility for the development of pneumocephalus would be any leak in the closed drainage system of the previous EVD drain. Properly layered closure of the skin in VP shunt surgery is the most important factor for prevention of this rare complication.
The pneumocephalus in our case most likely would have occurred either during trephination of burr hole or while incising the dura prior to ventricular tap. Other probable reasons were ruled out since the EVD was clamped (as open EVD would have caused resulted in negative pressure and thereby pneumocephalus) and we also ensured the air locked system of the EVD circuit (as breach in the same would let the air get sucked in).

The dry tap, as seen in our case, can lead to multiple attempts to attain the correct shunt trajectory, thereby increasing the risk of false trajectories and track hematomas. If there had been no EVD, then this would have led to termination of the procedure, thereby adding to the morbidity and risk of subsequent surgery. One alternative to our approach would be the use of intra-operative CT scan to ensure the diagnosis. Unfortunately this is not currently possible in developing countries like ours. We can, if available, take help of neuro-navigation tools to ensure the correct trajectory to the ventricles even in cases were in pneumocephalus occurs. This can reduce the added burden of subsequent surgeries and associated risk of anesthesia.

There is also risk of seizure and rapid neurological deterioration due to tension pneumocephalus. Once this occurs, close monitoring of the patient, rapid and accurate identification of tension pneumocephalus, and immediate surgical intervention is life-saving. Gore et al. ${ }^{8}$ have advocated the use of $100 \%$ oxygen for rapid resolution of pneumocephalus.

In conclusion, though VP shunting is one of the most common surgical procedures performed in neurosurgery, strict adherence to basic principles should be followed during the procedure so as to prevent avoidable complications such as in our case which may in times lead to sudden deterioration in the patient and also add to diagnostic and therapeutic dilemma to the concerned surgeons. One advantage in this case was the presence of an EVD as a safety bypass for CSF diversion. The limitations of our approach can be attributed to the unavailability of intra-operative CT scan and neuronavigation techniques which would have aided in early diagnosis and management in this scenario.

\section{Consent}

Both written and verbal informed consent for publication of images and clinical data related to this case was sought and obtained from the wife of the patient.

\section{Author contributions}

Dr Sunil reviewed the literature, designed the study and formatted the paper. Dr Binod revised and edited the final format.

\section{Competing interests}

The authors declared no competing interests.

\section{Grant information}

The authors declared that no funding was involved in supporting this work. 
1. Barada W, Najiar M, Beydoun A: Early onset tension pneumocephalus following ventriculoperitoneal shunt insertion for normal pressure hydrocephalus: a case report. Clin Neurol Neurosurg. 2009; 111(3): 300-302.

PubMed Abstract | Publisher Full Text

2. Kawajiri K, Matsuoka Y, Hayazaki K: Brain tumors complicated by pneumocephalus following cerebrospinal fluid shunting--two case reports. Neurol Med Chir (Tokyo). 1994; 34(1): 10-14.

PubMed Abstract | Publisher Full Text

3. Monas J, Peak DA: Spontaneous tension pneumocephalus resulting from a scalp fistula in a patient with a remotely placed ventriculoperitoneal shunt. Ann Emerg Med. 2010; 56(4): 378-381.

PubMed Abstract | Publisher Full Text

4. Tuğcu B, Tanriverdi $O$, Günaldi $O$, et al:: Delayed intraventricular tension pneumocephalus due to scalp-ventricle fistula: a very rare complication of shunt surgery. Turk Neurosurg. 2009; 19(3): 276-280.

PubMed Abstract
5. Ugarizza LF, Cabezudo JM, Lorenzana LM, et al: Delayed pneumocephalus in shunted patients. Report of three cases and review of the literature.

Br J Neurosurg. 2001; 15(2): 161-167.

PubMed Abstract | Publisher Full Text

6. Reasoner DK, Todd MM, Scamman FL, et al.: The incidence of pneumocephalus after supratentorial craniotomy. Observations on the disappearance of intracranial air. Anesthesiology. 1994; 80(5): 1008-1012.

PubMed Abstract | Publisher Full Text

7. Ishiwata $\mathrm{Y}$, Fujitsu K, Sekino T, et al:: Subdural tension pneumocephalus following surgery for chronic subdural hematoma. J Neurosurg. 1988; 68(1): $58-61$

PubMed Abstract | Publisher Full Text

8. Gore PA, Maan H, Chang S, et al:: Normobaric oxygen therapy strategies in the treatment of postcraniotomy pneumocephalus. J Neurosurg. 2008; 108(5): 926-929.

PubMed Abstract | Publisher Full Text 


\section{Open Peer Review}

\section{Current Peer Review Status:}

\section{Version 2}

Reviewer Report 13 May 2016

https://doi.org/10.5256/f1000research.7698.r13750

(C) 2016 Satyarthee $\mathbf{G}$ et al. This is an open access peer review report distributed under the terms of the Creative Commons Attribution License, which permits unrestricted use, distribution, and reproduction in any medium, provided the original work is properly cited.

\section{Guru Dutta Satyarthee}

Department of Neurosurgery, All India Institute of Medical Sciences, New Delhi, Delhi, India

\section{Luis Rafael Moscote-Salazar}

Neurosurgery-Critical Care, RED LATINO. Latin American Trauma \& Intensive Neuro-Care Organization, Bogota, Colombia

The authors provide important guidelines for the evaluation and management of hydrocephalus developing in the post-craniotomy follow-up period after surgical traumatic acute subdural evacuation. The authors presented an interesting case, which presented with gait abnormality associated with falling back tendency and underwent craniotomy surgery two months earlier for evacuation acute subdural hematoma. A cranial computed tomography revealed presence of hydrocephalus. In the standard management of post traumatic craniotomy development of hydrocephalus, it is essential to evaluate the possible causes, degree of intracranial pressure rise, evaluating beneficial effect of cerebrospinal fluid diversion procedure i.e. ventriculoperitoneal shunt or thecoperitoneal shunt, assessment of CSF protein level, and exclusion of associated indolent meningitis as possible causes.

Ideally for excluding ex-vacuo post-traumatic hydrocephalus development, CSF sampling can be done through lumbar drainage or by placing external ventricular drainage and assessing initial CSF egress pressure with manometry for selection of pressure range and most suitable type of future shunt requirement, cytological, protein level for suitability of shunt functioning after shunt insertion; as very high protein level can be relative contraindication for shunt, biochemical study and culture sensitivity studies to exclude infective pathology and assessing Mini mental scale for cognitive assessment and gait changes. The patient shows improvement following CSF drainage CSF diversion surgery in the form of thecoperitoneal or ventriculoperitoneal shunt, however the former is the preferred choice. ${ }^{1}$

Development of pneumocephalus requires communication between arachnoid membrane and associated defect in the dura, calvarium and communication to the external environment. As CSF egresses, air enters the intracranial cavity and development of pneumocephalus. The "ball valve" mechanism was postulated by Dandy, as air travels in only one direction ${ }^{2}$. After air entering the 
cranial cavity leads to rise in the intracranial pressure ${ }^{3}$.

The other postulates for tension pneumocephalus is the "Inverted-soda-bottle effect", proposed by Horowitz ${ }^{4}$. The author postulated negative intracranial pressure resulting from excessive loss of CSF through an iatrogenic lumbar drain or settling into the distendable spinal subarachnoid space or simply drainage via normal pathways with physiologic activity such as inspiration or the Valsalva manoeuvre 4 . However, when there are fistulous communications between the intracranial and outer environment, air can enter the intracranial space as a consequence of negative pressure gradient $3,5-6$. As the authors' case had EVD, that might have unfortunately disconnected and leak of CSF led to development of tension pneumocephalus. In cases of dry tap, insertion of the ventricular end is specially challenging and options include abandoning the procedure, getting an intraoperative cranial CT scan or help of an endoscope, or image guidance or infusing fluid through the EVD into the ventricle thereby distending the ventricle prior to reattempting Ventricular catheter insertion. However, dry tap is really a neurosurgical emergency needing tactful management, which depends on available facility at surgical centre including image guidance, intraoperative CT scan facility, endoscope facility and expertise of surgical team.

\section{References}

1. Agrawal D, Pandey N, Sinha S, Gupta D, et al.: Subdural effusion with ventriculomegaly after decompressive craniectomy for traumatic brain injury: A challenging entity. The Indian Journal of Neurotrauma. 2014; 11 (2): 97-102 Publisher Full Text

2. DANDY W: PNEUMOCEPHALUS (INTRACRANIAL PENUMATOCELE OR AEROCELE). Archives of Surgery. 1926; 12 (5). Publisher Full Text

3. Lee SH, Koh JS, Bang JS, Kim MC: Extensive tension pneumocephalus caused by spinal tapping in a patient with Basal skull fracture and pneumothorax.J Korean Neurosurg Soc. 2009; 45 (5): 318-21 PubMed Abstract | Publisher Full Text

4. HOROWITZ M: INTRACRANIAL PNEUMOCOELE. AN UNUSUAL COMPLICATION FOLLOWING MASTOID SURGERY.J Laryngol Otol. 1964; 78: 128-34 PubMed Abstract

5. Rathore AS, Satyarthee GD, Mahapatra AK: Post-Traumatic Tension Pneumocephalus: Series of Four Patients and Review of the Literature.Turk Neurosurg. 2016; 26 (2): 302-5 PubMed Abstract | Publisher Full Text

6. Satyarthee GD, Mahapatra AK: Tension pneumocephalus following transsphenoid surgery for pituitary adenoma - report of two cases.J Clin Neurosci. 2003; 10 (4): 495-7 PubMed Abstract

Competing Interests: No competing interests were disclosed.

We confirm that we have read this submission and believe that we have an appropriate level of expertise to confirm that it is of an acceptable scientific standard.

\section{Version 1}

Reviewer Report 24 September 2015

https://doi.org/10.5256/f1000research.7251.r10474 
(C) 2015 Bosnjak R. This is an open access peer review report distributed under the terms of the Creative Commons Attribution License, which permits unrestricted use, distribution, and reproduction in any medium, provided the original work is properly cited.

\section{Roman Bosnjak}

Department of Neurosurgery, University Medical Centre Ljubljana, Ljubljana, Slovenia

The authors analysed dry tap during ventriculostomy in the presence of EVD inserted few days before.

Their explanations are reasonable. But there might be additional explanations.

The EVD was inserted to rule out ex vacuo hydrocephalus. CSF egressed under pressure. Here the authors could insert VP shunt on first occasion (without previous EDV).

There is no report on patient's condition between EVD and VP insertion. If it improved and remained stable, no significant tension hydrocephalus is expected to evolve. It is my theory that the air was sucked into the ventricles and trapped subdurally at the time of VP shunt insertion when EDV was probably not stopped enough long time before VP insertion.

EDV produced some minor negative pressure. During attempts of inserting ventricular catheter of VP shunt produced sucking of the air into the ipsilateral ventricle and trapping it there. Similarly, during trephination of a burr hole for insertion of VP shunt and cutting the dura, some air was sucked subdurally on that side.

As slowly evolving postraumatic hydrocephalus is mainly of malabsorptive communicative type, lumbar drainage is less invasive attempt to reveal ex vacuo hydrocephalus than EDV. EDV or LD is stopped cca. 4-6h before inserting VP catheter to reexpand the ventricles and ease targeting.

Competing Interests: No competing interests were disclosed.

\section{I confirm that I have read this submission and believe that I have an appropriate level of expertise to confirm that it is of an acceptable scientific standard, however I have significant reservations, as outlined above.}

Author Response 24 Sep 2015

Sunil Munakomi, College of Medical Sciences, Bharatpur, Nepal

Respected sir,

Thank you for your report.

We place the EVD in our ICU in suspected cases of hydrocephalus and then plan for the shunting if there is egress of CSF under pressure and neurological improvement in the patient. This case showed neurological improvement after EVD placement. The repeat CT after the shunt did not reveal pneumocephalus. We routinely do clamp the EVD 6 hours prior to the procedure to facilitate the tap.As you have correctly mentioned, the 
pneumocephalus might have resulted either during the trephination or during corticol incision prior to ventricular tap.Sorry to have missed these points in our paper.

Competing Interests: No conflict of interest

Reviewer Report 11 August 2015

https://doi.org/10.5256/f1000research.7251.r9362

(C) 2015 Gao G. This is an open access peer review report distributed under the terms of the Creative Commons Attribution License, which permits unrestricted use, distribution, and reproduction in any medium, provided the original work is properly cited.

\section{Guo-Yi Gao}

Department of Neurosurgery, Shanghai Jiao Tong University, Shanghai, China

VP shunt is the most frequent surgical technique in neurosurgery to treat hydrocephalus related with trauma, SAH, tumor and other brain diseases. Dry tap, which is a rare episode during the shunt operation, may cause confused decision and leading to complications. In this report, authors described the details of the dry tap and analysis the possible reasons behind, which is helpful for neurosurgeons to prevent this rare complication in clinical settings.

Competing Interests: No competing interests were disclosed.

I confirm that I have read this submission and believe that I have an appropriate level of expertise to confirm that it is of an acceptable scientific standard.

The benefits of publishing with F1000Research:

- Your article is published within days, with no editorial bias

- You can publish traditional articles, null/negative results, case reports, data notes and more

- The peer review process is transparent and collaborative

- Your article is indexed in PubMed after passing peer review

- Dedicated customer support at every stage

For pre-submission enquiries, contact research@f1000.com 